\title{
The Book of Mormon: A Biography, by Paul C.
} Gutjahr

Lives of Great Religious Books | Princeton: Princeton University Press, 20I 2 |xix+255 pages | ISBN: 978-0-69I-I4480-I (hardback) $\$ 24.95$

This is a really delightful book which forms part of a new series by Princeton on the Lives of Great Religious Books, which has already included publications on the Tibetan Book of the Dead, Bonhoeffer's Letters

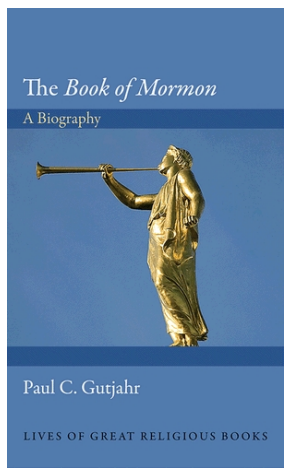
and Papers from Prison (by Martin Marty), the I Ching, and Augustine's Confessions. Projected volumes seem to treat individual books of the Bible and I see that Bruce Chilton will write on the Book of Revelation, while others have been commissioned on the Dead Sea Scrolls, C. S. Lewis's Mere Christianity, and the Book of Common Prayer, as well as a range of texts from other world religions.

It is not immediately apparent that a book has a life history-does a book grow old? But books certainly do have histories, and in an age which seems inclined to abandon printed publications it is valuable to realise how much cultural history is bound up in these works. Gutjahr's work is essentially a cultural history of Mormonism, although from a rather narrow angle. The book carefully eschews all the vast debates that have raged around the volume and it is not immediately clear from the volume whether the author is a member of the Latter-day Saints or not-although the neutral tone might 
suggest that he is not, and the previous publications of this professor of English at Indiana University include studies of Charles Hodge, and a history of the Bible in nineteenth-century America. But literature on the Mormons has often been polemical, and much of the really good historical study has come from Mormon scholars, although they are often somewhat estranged from the institutions of the church.

The book is written around the motif of the life of a tree, not a human, and falls into three parts, "Germination," "Budding" and "Flowering." So this is a book about the appearance of the Book of Mormon as it appeared to the onlooker. There is much in the book about changing texts, and Mormons do allow that their current prophet can order fiat changes in the text-which is essential because there are no originals to go back to. There is very little about the order and content of the Book of Mormon. A particularly interesting aspect of the book is the author's claim that many Mormons were until recently much better acquainted with the Bible than with the Book of Mormon, and that only in recent years have there been strong injunctions within the church to read it. Certainly my first copy of the Book of Mormon had handwritten notes placed there by a missionary training, going through a tiny catena of texts which were designed to show that the book was selfvalidating, and using arguments based on the testimonies in the front of the book by the witnesses who had seen-or nearly seen — the golden plates, as well as references in the Old Testament which bolstered the claim to a third testament. In this sense the Book of Mormon was a long and complex tale, as Gutjahr notes, of alleged tribal histories and the details of the characters are somewhat complex and tedious. At this point I must confess to a certain surprise that Gutjahr did not treat us to a literary analysis of a book which is difficult to read simply because of its clumsy attempt at Jacobean English and (at least in the traditional text) presented verse by verse rather than in paragraphs.

However rather than lament what was not written, I must express delight in the tone of this book which lays a platform for scholarship about the Latter-day Saints which is about their central text but is not polemical. Gutjahr argues that this book is surely one of the great achievements of American culture, and he traces the growth in publication of the text so that I 50 million copies have been distributed in a vast array of languages, following a very conservative principle of interpretation. The Latter-day Saints are a text-based religion. There is no mention in this volume of the Maori translation, but it has a colourful history of its own, with the first translation (later recognised 
as rather clumsy) supposedly produced in near miraculous circumstances of its own. But my own research suggests that Maori Mormons held one or two key values about a new revelation, but talked little about the content of the book. So this bears out Gutjahr's interpretation.

Gutjahr's account of the writing (or translation) of the book of Mormon carefully picks its way through the various controversial interpretations of these circumstances. He notes that from the earliest days there were essentially three interpretations of the circumstances of the writing of the book, the supernaturalist approach which believed that this was a new divine revelation, the plagiarist view that emphasised sources which they believed Smith had used, and the naturalist school which emphasised Joseph Smith's fertile imagination. The middle school might well have received more attention from a literary critic than we find here, but the author places his focus on the changes in the editions of the Book of Mormon from its first edition in I 830 to the 1840 edition and a range of different books, although none formally advocated polygamy despite evidence that it was practised from about I 84I. For Mormons the changing requirements of other texts were perhaps more influential. One particular interest of this book is that it highlights what happened to the so-called "Reorganised Church" (or RLDS) which continued to be led by a descendant of Joseph Smith, and now seems to have abandoned any literal reading of the Book of Mormon. Meanwhile the increasingly institutionalised Utah-based church has become more and more systematic in its translation and distribution of the sacred text, and shows no signs of regarding it in a metaphorical light. The work of Hugh Nibley in attempting to verify the Book of Mormon from Middle Eastern sources, and the work of John Sorenson to locate it in Central America are striking examples of this very literal approach to the text, although so far they have yielded no fruits. Meanwhile illustrated editions have fixed images of the events of the book, and these are quite familiar in the way the Book of Mormon is promoted in New Zealand and the Pacific.

As I was writing this review news came that the Broadway musical on the Book of Mormon which the author discusses in his final chapter has arrived in London's West End. The Mormons in unusually magnanimous spirit have advertised their Book in the show's programme. I did find the lack of theological engagement with this generation of Latter-day Saints a disappointment, as in my experience, some of the eager searches for archaeological evidence for the Book of Mormon are regarded with some amusement by informed Mormons, and the author says nothing about the controversy of the I 980 os 
over the forged Salamander letters in which the Church of Jesus Christ of Latter-day Saints seemed to be alarmed and anxious to suppress what turned out to be false allegations about letters by Joseph Smith suggesting that he was interested in magical practices.

So this is a fascinating read, if frustrating at times. It is also an a charming little book, in a neat octavo size, only issued in hardback, on fine paper, with maybe thirty fine black and white illustrations. It was in every sense a pleasure to read.

Peter Lineham

Massey University 